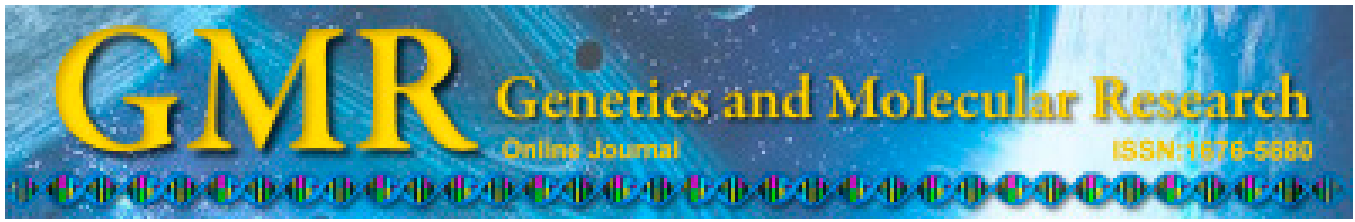

\title{
Association between $\beta 1$ adrenergic receptor gene Arg389Gly polymorphism and risk of heart failure: a meta-analysis
}

\author{
S.T. Ma ${ }^{1,2}$, W. Zhao ${ }^{3}$, B. Liu' ${ }^{2}$, R.Y. Jia ${ }^{2}$, C.J. Zhao ${ }^{2}$ and L.Q. Cui ${ }^{1}$ \\ ${ }^{1}$ Department of Cardiology, \\ The Provincial Hospital Affiliated to Shandong University, \\ Jinan, Shandong, China \\ ${ }^{2}$ Department of Cardiology, Jinan Institute of Cardiovascular Disease, \\ The Fourth People's Hospital of Jinan, Jinan, Shandong, China \\ ${ }^{3}$ Department of Cardiology, Shandong Jiaotong Hospital, Shandong, China \\ Corresponding author: L.Q. Cui \\ E-mail: cui_lianqun@126.com
}

Genet. Mol. Res. 14 (2): 5922-5929 (2015)

Received August 11, 2014

Accepted February 10, 2015

Published June 1, 2015

DOI http://dx.doi.org/10.4238/2015.June.1.9

\begin{abstract}
Numerous studies have evaluated the association between Arg389Gly polymorphism in the $\beta 1$ adrenergic receptor gene and heart failure risk. However, the specific association is still controversial. We performed a meta-analysis of all case-control studies that evaluated the association between Arg389Gly polymorphism and heart failure in humans. Studies were identified in the PubMed, Embase, and China National Knowledge Infrastructure databases. Two reviewers independently assessed the studies. Six case-control studies with a total of 1736 participants were included in the meta-analysis, including 882 cases with heart failure and 854 controls, and our results showed no association between the Arg389Gly polymorphism and heart failure [ArgArg vs GlyGly: odds ratio $(\mathrm{OR})=0.84,95 \%$ confidence interval (CI) 0.59-1.20; ArgArg vs ArgGly: OR = 0.95, 95\%CI 0.781.16; dominant model: $\mathrm{OR}=1.08,95 \% \mathrm{CI} 0.89-1.31$; recessive model:
\end{abstract}


$\mathrm{OR}=0.96,95 \% \mathrm{CI} 0.69-1.35]$. No publication bias was found in the present study (all $\mathrm{P}$ values $>0.05$ ). In conclusion, the $\beta 1$ adrenergic receptor gene Arg389Gly polymorphism might not be associated with heart failure risk. Further large and well-designed studies are needed to confirm this conclusion.

Key words: Arg389Gly; Polymorphism; Heart failure; Gene; $\beta 1$ adrenergic receptor; Meta-analysis

\section{INTRODUCTION}

Heart failure is a clinical syndrome characterized by impaired contractile function of the heart, and represents the final pathway of a variety of diseases. In the last few years, heart failure has been the leading cause of morbidity and mortality worldwide (Bleumink et al., 2004). It is estimated that by 2030, an additional 3 million people in the USA will have developed heart failure, a 25.0\% increase in prevalence from 2010 (Heidenreich et al., 2011). Despite much investigation, the causes are not yet fully understood. Although coronary heart disease and hypertension remain the major causes of heart failure, other underlying conditions include idiopathic dilated cardiomyopathy, valvular congenital heart disease, and diabetes mellitus. In addition, genetic factors also play important roles in the pathogenesis of heart failure (Morita et al., 2005).

Norepinephrine release is increased 5- to 10-fold in the failing heart and it causes ischemia, apoptosis, pathologic hypertrophy, and arrhythmias. Norepinephrine has higher affinity for $\beta 1$-receptors than the other subtypes of adrenergic receptor such as $\beta 2$-receptors. In spite of $\beta 1$ receptor downregulation, most of the total adrenergic receptor occupancy is of the $\beta 1$-subtype (Bristow et al., 2003). $\beta 1$-receptors are $G$ protein-coupled receptors that trigger signaling via adenylate cyclase, cyclic adenosine monophosphate, and protein kinase A. This signaling pathway regulates the sarcoplasmic calcium concentration and increases cardiomyocyte contractility (Holthoff et al., 2012). Evidence from both animal- and patient-based studies has indicated that the $\beta 1$-receptors may play an important role in the development and clinical course of progressive cardiac dilatation and heart failure (Jahns et al., 1999; Nikolaev et al., 2007).

The human $\beta 1$ adrenergic receptor has 45 amino acids and is encoded by an intronless gene located on chromosome 10q24-26. A G $\rightarrow$ C exchange at 1165 base pairs (bp) in the $\beta 1$ adrenergic receptor gene causes amino acid substitution of Gly by Arg at residue 389 (Gly389Arg). In vitro studies have shown that the $\beta 1$-receptor Arg389 variant has enhanced G protein coupling with a 2- to 3-fold greater cyclic adenosine monophosphate and inotropic response to agonist stimulation, compared with the Gly389 allele (Mason et al., 1999). Thus, it seems that the $\beta 1$ adrenergic receptor gene Arg389Gly polymorphism could play a role in the pathogenesis of heart disease.

To date, many studies have been performed to evaluate the relationship between the Arg389Gly polymorphism in the $\beta 1$ adrenergic receptor gene and heart failure risk. However, the results remain controversial, possibly owing to small sample sizes, low statistical power, and clinical heterogeneity (Ammar et al., 2012). In the present study, we investigated whether the Arg389Gly polymorphism is associated with heart failure risk by performing a meta-analysis. 


\section{MATERIAL AND METHODS}

\section{Selection of studies}

We conducted a literature search in PubMed, Embase, and China National Knowledge Infrastructure databases (including records entered up to June 2014) using the following key words: "heart failure", " $\beta 1$ adrenergic receptor gene", "Arg389Gly", and "gene polymorphism". If sequential or multiple publications from the same data occurred, the publication that reported data from the largest or most recent study was included. No restriction was made on time-period, sample size, population, language, or type of report, but all studies had been conducted on human subjects.

\section{Inclusion and exclusion criteria}

The following criteria were used to include published studies: 1) case control studies; 2) studies assessing the association of Arg389Gly polymorphism in the $\beta 1$ adrenergic receptor gene with heart failure risk; 3) providing sufficient information for estimating the odds ratio (OR) with its $95 \%$ confidence interval $(95 \% \mathrm{CI})$; and 4$)$ providing available data to acquire genotype frequency of Arg389Gly polymorphism. Major exclusion criteria were: 1) review, editorial, or comment; 2) no available genotype frequency; and 3) duplicated studies.

\section{Data extraction}

Two reviewers (S.T.M. and B.L.) independently performed data extraction and then checked the results together. The following information was extracted from the included studies: first author, year of publication, area, number of cases and controls, genotype frequencies in cases and controls, and evidence of Hardy-Weinberg equilibrium (HWE) in controls (Table 1). For conflicting evaluations, an agreement was reached following a discussion.

\section{Statistical analysis}

The Fisher exact test was used to assess the HWE with the significance set at $\mathrm{P}<0.05$. The association between the Arg389Gly polymorphism and heart failure was compared using the OR corresponding to a $95 \% \mathrm{CI}$. The pooled ORs were performed for a co-dominant model (ArgArg vs GlyGly, ArgArg vs ArgGly), a dominant model (GlyGly + ArgGly vs ArgArg), and a recessive model (ArgArg + ArgGly vs GlyGly). The Q-test and the $I^{2}$ test were performed to quantify the proportion of the total variation due to heterogeneity. $\mathrm{I}^{2}$ ranges from 0 to $100 \%$. A value of $0 \%$ indicates no observed heterogeneity, and larger values reflect increasing heterogeneity, with $25 \%$ regarded as low, $50 \%$ as moderate, and $75 \%$ as severe heterogeneity. When the effects were assumed to be homogeneous ( $\left.\mathrm{P}>0.1, \mathrm{I}^{2}<50 \%\right)$, the fixed-effects model; otherwise, the random-effects model was used. Subgroup analysis based on nationality was used to explore and to explain the diversity among the results of different studies. Sensitivity analysis was performed through random-effects model values compared with the fixed effect. Publication bias was investigated by Begg's funnel plot. All analyses were performed using STATA version 12.0 (Stata Corporation; College Station, TX, USA). All P values were 2 -sided. To ensure the reliability and accuracy of the results, two authors uploaded the data. 


\section{RESULTS}

\section{Characteristics of studies included}

The search strategy retrieved 74 potentially relevant studies. Based on the inclusion criteria, only six case-control studies (Small et al., 2002; Covolo et al., 2004; Nonen et al., 2005; Yu et al., 2006; Biolo et al., 2008; Pereira et al., 2013) with full text were included in this meta-analysis and 68 studies were excluded. The flow chart of study selection is summarized in Figure 1.

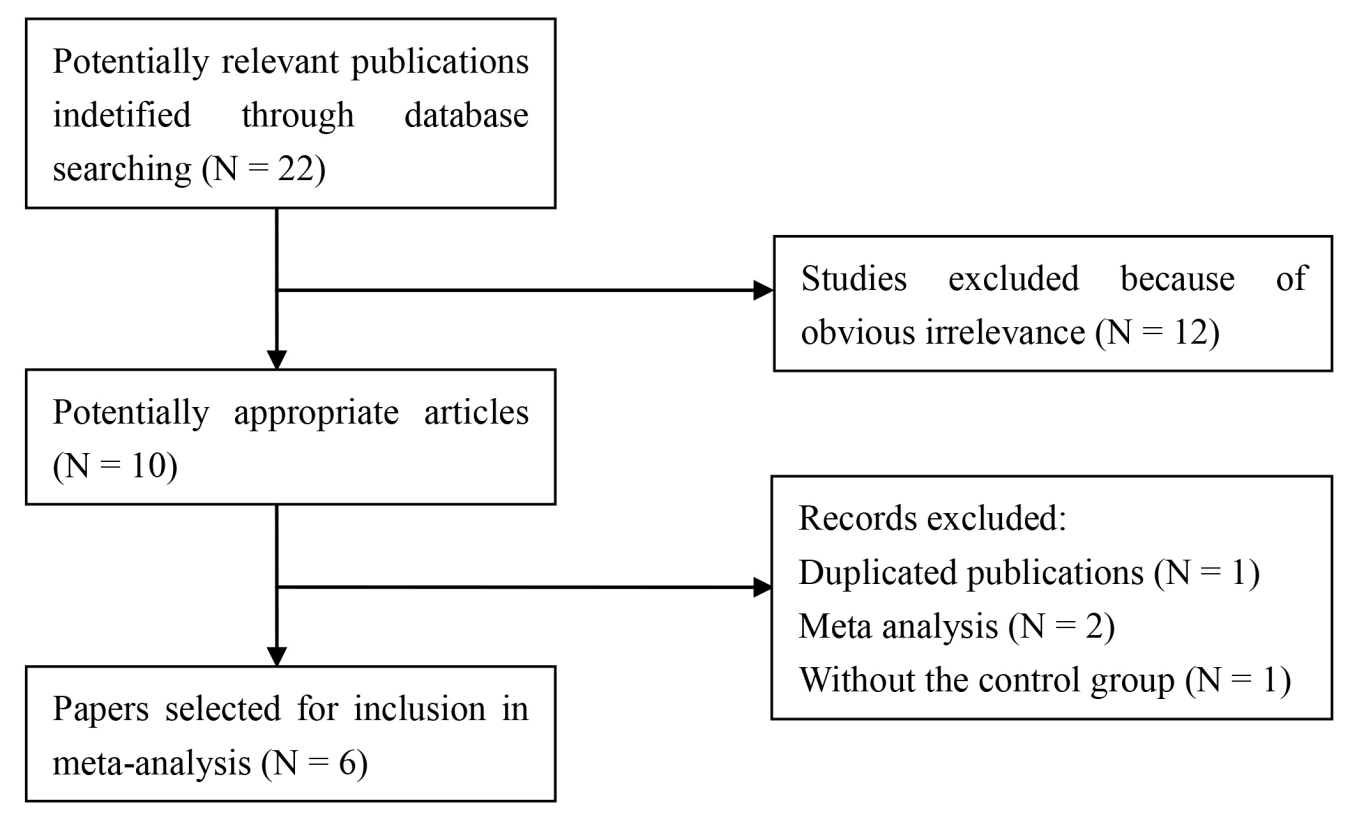

Figure 1. Flow diagram of study searching and selection process.

These six case-control studies included a total of 882 heart failure cases and 854 healthy controls. All studies included were case-control studies, which evaluated the association between the Arg389Gly polymorphism in the $\beta 1$ adrenergic receptor gene and susceptibility to heart failure. The year of publication of the included studies ranged from 2000 to 2014 2014. The source of controls was based on healthy populations. The genotype frequencies of the controls from six studies were in agreement with HWE. The study characteristics are presented in Table 1.

\section{Quantitative synthesis}

The combined results of Arg389Gly polymorphism and heart failure risk are summarized in Figure 2 and Table 2. 
Table 1. Characteristics of the studies included for meta-analysis.

\begin{tabular}{|c|c|c|c|c|c|c|c|c|c|c|}
\hline \multirow[t]{2}{*}{ Study included } & \multirow[t]{2}{*}{ Area } & \multirow[t]{2}{*}{ Race } & \multirow[t]{2}{*}{ Cases/Controls } & \multicolumn{3}{|c|}{ Genotypes for cases } & \multicolumn{3}{|c|}{ Genotypes for controls } & \multirow[t]{2}{*}{ HWE test } \\
\hline & & & & ArgArg & ArgGly & GlyGly & ArgArg & ArgGly & GlyGly & \\
\hline Small et al. (2002) & USA & Mixed & $78 / 84$ & 23 & 36 & 19 & 23 & 48 & 13 & 0.14 \\
\hline Covolo et al. (2004) & Italy & Caucasians & $256 / 230$ & 119 & 116 & 21 & 122 & 90 & 18 & 0.81 \\
\hline Nonen et al. (2005) & Japan & Asians & $91 / 119$ & 60 & 26 & 5 & 79 & 35 & 5 & 0.66 \\
\hline Yu et al. (2006) & China & Asians & $110 / 100$ & 54 & 42 & 9 & 53 & 40 & 7 & 0.88 \\
\hline Biolo et al. (2008) & Brazil & Mixed & $201 / 141$ & 110 & 77 & 14 & 81 & 52 & 8 & 0.93 \\
\hline Pereira et al. (2013) & Brazil & Mixed & $146 / 180$ & 71 & 58 & 17 & 82 & 77 & 21 & 0.65 \\
\hline
\end{tabular}

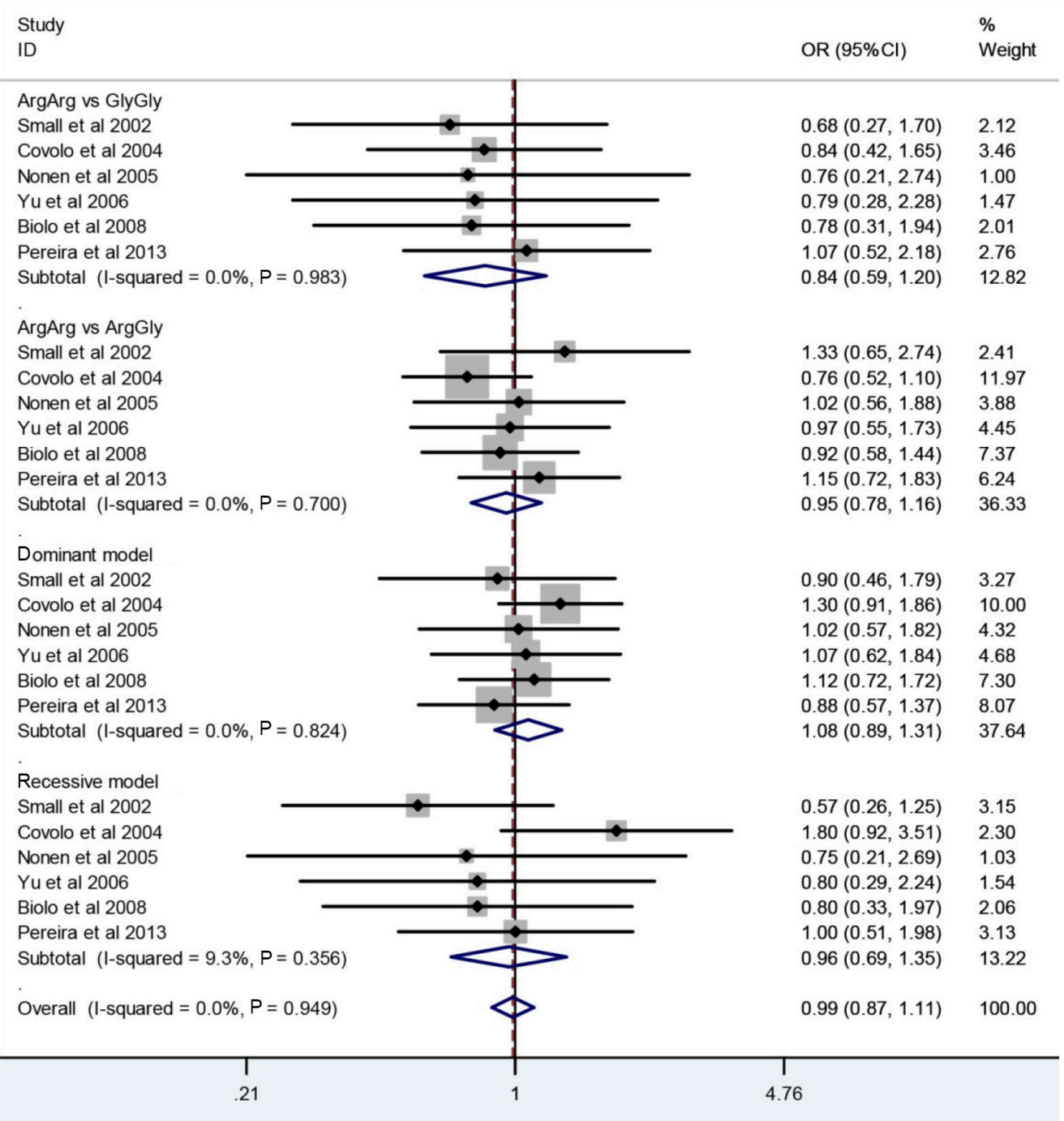

Figure 2. Forest plot of heart failure risk associated with $\beta 1$ adrenergic receptor gene Arg389Gly polymorphism in overall population. The squares and horizontal lines correspond to the study-specific odds ratios (OR) and $95 \%$ confidence intervals (CI). 
Table 2. Summary ORs and 95\%CI of Arg389Gly polymorphism with heart failure risk.

\begin{tabular}{|c|c|c|c|c|c|c|c|c|c|}
\hline \multirow[t]{2}{*}{ Subgroup } & \multirow[t]{2}{*}{ Genetic model } & \multirow{2}{*}{$\frac{\text { Sample size }}{\text { Case/Control }}$} & \multirow[t]{2}{*}{ Type of model } & \multicolumn{2}{|c|}{ Test of heterogeneity } & \multicolumn{2}{|c|}{ Test of association } & \multicolumn{2}{|c|}{ Test of publication bias } \\
\hline & & & & $\mathrm{I}^{2}$ & $\mathrm{P}$ & OR & $95 \% \mathrm{CI}$ & $\mathrm{z}$ & $\mathrm{P}$ \\
\hline \multirow[t]{4}{*}{ Overall } & ArgArg vs GlyGly & $882 / 854$ & Fixed & $0.0 \%$ & 0.98 & 0.84 & $0.59-1.20$ & 0.00 & 1.00 \\
\hline & ArgArg vs ArgGly & & Fixed & $0.0 \%$ & 0.70 & 0.95 & $0.78-1.16$ & 0.00 & 1.00 \\
\hline & Dominant model & & Fixed & $0.0 \%$ & 0.82 & 1.08 & $0.89-1.31$ & 0.00 & 1.00 \\
\hline & Recessive model & & Fixed & $9.3 \%$ & 0.36 & 0.96 & $0.69-1.35$ & 0.00 & 1.00 \\
\hline
\end{tabular}

$\mathrm{OR}=$ odds ratio; $\mathrm{CI}=$ confidence interval.

Four models suggested remarkable between-study heterogeneity. Thus, both the fixed-effects model and the random-effects model were used to calculate the pooled estimates. Meta-analysis results identified no significant association between Arg389Gly polymorphism and susceptibility to heart failure (ArgArg vs GlyGly: $\mathrm{OR}=0.84,95 \% \mathrm{CI} 0.59-1.20$; $\operatorname{Arg} \operatorname{Arg} v s$ ArgGly: OR $=0.95,95 \%$ CI 0.78-1.16; dominant model: $\mathrm{OR}=1.08,95 \% \mathrm{CI} 0.89-1.31$; recessive model: $\mathrm{OR}=0.96,95 \% \mathrm{CI} 0.69-1.35$ ).

\section{Publication bias and sensitivity analysis}

Sensitivity analyses were conducted by altering the statistic models. No material alteration was detected, indicating that our results were statistically robust. Publication bias of the literature was assessed by Begg's funnel plot (Figure 3 and Table 2).

The funnel plot was used to measure asymmetry. The results of the Begg's funnel plot test are shown in Table 2. The results showed that there was no publication bias (all $\mathrm{P}$ values $>0.05$ ).

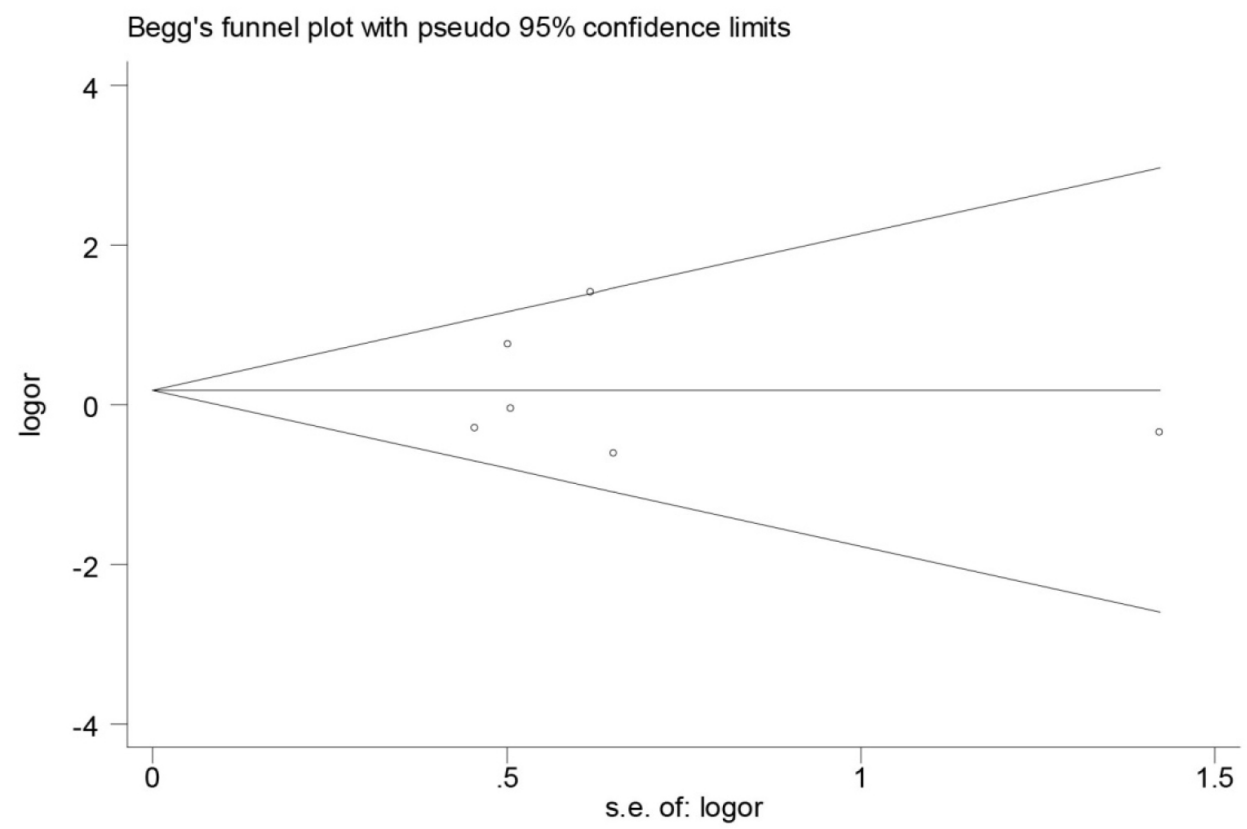

Figure 3. Funnel plot of $\beta 1$ adrenergic receptor gene Arg389Gly polymorphism and susceptibility of heart failure. 


\section{DISCUSSION}

Heart failure is a complex pathophysiologic state in which delivery of blood and nutrients is inadequate for tissue requirements. Although the cause of most heart failure is well known, the disease has proven difficult to diagnose early and treat successfully, reflecting limited advances in our understanding of the molecular mechanisms underlying heart carcinogenesis and individual susceptibility to heart failure. As is known, genetic polymorphisms altering the level of protein expressed would be anticipated to have a substantial influence on disease activity (Tahara et al., 2009). Recently, a variety of studies have focused on the association between the Arg389Gly polymorphism in the $\beta 1$ adrenergic receptor gene and heart failure. However, the observed associations of these studies were inconclusive. The most likely reason for the inconsistencies among these studies is that they are single case-control studies with small sample sizes. To help resolve these conflicting results, we conducted this meta-analysis to combine the same kind of studies to increase the sample size and statistical power, and thereby achieve a more authentic result.

To the best of our knowledge, this is the first meta-analysis assessing the relationship between Arg389Gly polymorphism and the risk of heart failure. Our meta-analysis quantitatively assessed the association between Arg389Gly polymorphism and heart failure risk. The current meta-analysis included 882 heart failure patients and 854 controls, and explored the association between the Arg389Gly polymorphism of the $\beta 1$ adrenergic receptor gene and heart failure risk. The results of the present meta-analysis revealed that the Arg389Gly gene polymorphism is not associated with increased or decreased risk of heart failure (ArgArg vs GlyGly: OR $=0.84,95 \%$ CI 0.59-1.20; ArgArg vs ArgGly: OR = 0.95, 95\%CI 0.78-1.16; dominant model: $\mathrm{OR}=1.08,95 \% \mathrm{CI} 0.89-1.31$; recessive model: $\mathrm{OR}=0.96,95 \% \mathrm{CI} 0.69$ $1.35)$. Sensitivity analysis was performed by comparing the random-effects model values to the fixed-effects model values, and the result revealed that this meta-analysis was realistic and believable. There was no evidence of publication bias in this meta-analysis for Arg389Gly polymorphism (all $\mathrm{P}$ values $>0.05$ ).

There are several potential explanations for the negative results above. Firstly, most of the studies in our meta-analysis included few cases and controls, leading to lack of power to detect common small effects in genetic association studies of multifactorial characteristics (Colhoun et al., 2003). This problem might be resolved by increasing the sample sizes and collecting cases with strong genetic etiology or family history. Secondly, the negative effects may be partly attributable to the considerable heterogeneity between the studies included in the main analysis. Heterogeneity may result from the variations in genetic constitution and/or environmental traits across the populations, or differences in sample selection (e.g., age, gender, or diagnostic criteria), or the difference in the design of the studies. Finally, the potential influence of Arg389Gly polymorphism may be affected by gene-gene and geneenvironment interactions. In the future, polymorphisms within haplotypes combined with environmental interactions could be used as a risk stratification tool for heart failure rather than the individual polymorphism.

In conclusion, our meta-analysis indicates that Arg389Gly polymorphism in the $\beta 1$ adrenergic receptor gene was not associated with risk of heart failure. Large-scale case-control and population-based association studies are warranted to validate the risk identified in the current meta-analysis and investigate the potential gene-gene and gene-environment interactions on heart failure risk. 


\title{
Conflicts of interest
}

\author{
The authors declare no conflict of interest.
}

\section{REFERENCES}

Ammar M, Bouazizi F, Bouhaha R, Zaraa I, et al. (2012). Association analysis of LCE3C-LCE3B deletion in Tunisian psoriatic population. Arch. Dermatol. Res. 304: 733-738.

Biolo A, Clausell N, Santos KG, Salvaro R, et al. (2008). Impact of beta1-adrenergic receptor polymorphisms on susceptibility to heart failure, arrhythmogenesis, prognosis, and response to beta-blocker therapy. Am. J. Cardiol. 102: 726-732.

Bleumink GS, Knetsch AM, Sturkenboom MC, Straus SM, et al. (2004). Quantifying the heart failure epidemic: prevalence, incidence rate, lifetime risk and prognosis of heart failure The Rotterdam Study. Eur. Heart J. 25: 1614-1619.

Bristow MR, Feldman AM, Adams KF Jr and Goldstein S (2003). Selective versus nonselective beta-blockade for heart failure therapy: are there lessons to be learned from the COMET trial? J. Card. Fail. 9: 444-453.

Colhoun HM, McKeigue PM and Davey Smith G (2003). Problems of reporting genetic associations with complex outcomes. Lancet 361: 865-872.

Covolo L, Gelatti U, Metra M, Nodari S, et al. (2004). Role of beta1- and beta2-adrenoceptor polymorphisms in heart failure: a case-control study. Eur. Heart J. 25: 1534-1541.

Heidenreich PA, Trogdon JG, Khavjou OA, Butler J, et al. (2011). Forecasting the future of cardiovascular disease in the United States: a policy statement from the American Heart Association. Circulation 123: 933-944.

Holthoff HP, Zeibig S, Jahns-Boivin V, Bauer J, et al. (2012). Detection of anti- $\beta 1$-AR autoantibodies in heart failure by a cell-based competition ELISA. Circ. Res. 111: 675-684.

Jahns R, Boivin V, Siegmund C, Inselmann G, et al. (1999). Autoantibodies activating human B1-adrenergic receptors are associated with reduced cardiac function in chronic heart failure. Circulation 99: 649-654.

Mason DA, Moore JD, Green SA and Liggett SB (1999). A gain-of-function polymorphism in a G-protein coupling domain of the human $\beta 1$ adrenergic receptor. J. Biol. Chem. 274: 12670-12674.

Morita H, Seidman J and Seidman CE (2005). Genetic causes of human heart failure. J. Clin. Invest. 115: 518-526.

Nikolaev VO, Boivin V, Störk S, Angermann CE, et al. (2007). A novel fluorescence method for the rapid detection of functional ß1-adrenergic receptor autoantibodies in heart failure. J. Am. Coll. Cardiol. 50: 423-431.

Nonen S, Okamoto H, Akino M, Matsui Y, et al. (2005). No positive association between adrenergic receptor variants of alpha2cDel322-325, beta1Ser49, beta1Arg389 and the risk for heart failure in the Japanese population. Br. J. Clin. Pharmacol. 60: 414-417.

Pereira SB, Velloso MW, Chermont S, Quintão MM, et al. (2013). $\beta$-adrenergic receptor polymorphisms in susceptibility, response to treatment and prognosis in heart failure: implication of ethnicity. Mol. Med. Rep. 7: 259-265.

Small KM, Wagoner LE, Levin AM, Kardia SL, et al. (2002). Synergistic polymorphisms of beta1- and alpha2Cadrenergic receptors and the risk of congestive heart failure. N. Engl. J. Med. 347: 1135-1142.

Tahara T, Shibata T, Nakamura M, Yamashita H, et al. (2009). Effect of polymorphisms in the 3' untranslated region (3'UTR) of vascular endothelial growth factor gene on gastric cancer and peptic ulcer diseases in Japan. Mol. Carcinog. 48: 1030-1037.

Yu WP, Lou M, Deng B, Song HM, et al. (2006). $\beta 1$-adrenergic receptor (Arg389Gly) polymorphism and response to bisoprolol in patients with chronic heart failure. Zhonghua Xin Xue Guan Bing Za Zhi. 34: 776-780. 